It is difficult to offer an alternative to an infective explanation for the present findings. A possible relation between leukaemia in children under 1 year and maternal use of drugs such as marijuana ${ }^{17}$ cannot be relevant here, since the period in question (1950-3) long preceded any appreciable use of such drugs in Britain. Similarly, a hypothesis about mutations caused by delayed exposure to immunological challenges ${ }^{18}$ cannot be invoked since it would apply only in leukaemia occurring later than the ages that show the excess in this study.

The findings support the hypothesis that prompted this study - that the presence of large numbers of servicemen, particularly in rural districts, was conducive to an increase in the incidence of childhood leukaemia. They also point to an infection transmitted among adults, as also implied by a recent study of the effects of the population mixing associated with increases in commuting. ${ }^{19}$ The increase was greatest in children under 1 year, which suggests intrauterine infection with transmission from the serviceman population, presumably-directly or indirectly-by the husband.

We thank David Dipple, Gina Birch, and Janette Wallis for computing help, Helena Strange for clerical work, and Susan Hill for secretarial assistance. We are also grateful to Dr P Cook-Mozaffari, Dr R Mole, Professor P G Smith, Air Marshal Sir Thomas Stonor, and Professor N Wald for helpful comments. We thank the historical branches of the army and of the Royal Air Force and Mr Trevor Royle for information about national service.

The CRC Cancer Epidemiology Research Group is entirely funded by the Cancer Research Campaign, from which LJK holds a Gibb fellowship.
1 Kinlen LJ. Evidence for an infective cause of childhood leukaemia: com arison of a Scottish new town with nuclear reprocessing sites in Britain. Lancet 1988;ii:1323-7.

2 Kinlen LJ, Clarke K, Hudson C. Evidence from population mixing in British new towns 1946-85 of an infective basis of childhood leukaemia. Lance 1990 ;ii:577-82.

3 Registrar General. Decennial supplement England E Wales 1951. Area mortality. London: HMSO, 1958.

4 Royle T. The best years of their lives. The national service experience 1945-63. London: Michael Joseph, 1986.

5 Registrar General. Statistical review of England and Wales 1950 and 1951. Tables. Part I medical. London: HMSO, 1952, 1953: table 20.

6 General Register Office. Census 1951 England and Wales: occupation tables. London: HMSO, 1956.

7 Breslow NE, Day NE. Statistical methods in cancer research. Vol II. The design and analysis of cohort studies. Lyons: International Agency for Research on Cancer, 1987:71,96. (IARC Scientific Publications no 82.)

8 Breslow NE, Day NE. Statistical methods in cancer research. Vol II. The design and analysis of cohort studies. Lyons: International Agency for Research on Cancer, 1987:93-5. (IARC Scientific Publications no 82.)

9 Registrar General. Decennial supplement England and Wales 1951. Occupatione mortality part II. Volume 2: tables. London: HMSO, 1957:table 1.

10 Werner B. Infants aged under one in the census 1861-1981. Population Trends 1984;38:18-24.

11 Titmuss RM. Problems of social policy. In: Hancock WK, ed. History of the second world war. London: HMSO, 1950:245.

12 Campbell D. The unsinkable aircraft carrier. London: Michael Joseph, 1984.

3 Anderson RM, May RM. Directly transmitted infectious diseases: control by vaccination. Science 1982;215:1053-60.

14 Greaves MF. Subtypes of acute lymphoblastic leukemia: implications for pathogenesis and epidemiology. In: Magrath IT, O'Conor GT, Ramot B eds. Pathogenesis of leukemias and lymphomas: environmental influences. New York: Raven 1984 : 129-39.

15 Glover JA. Observations on the meningococcus carrier rate and their application to the prevention of cerebrospinal fever. In: Gordon MH application to the prevention of cerebrospinal fever. In:
Cerebro-spinal fever. Studies among the military forces, 1915-19.

16 Coburn AF, Young DC. The epidemiology of hemolytic streptococcus during world war II in the United States Navy. Baltimore: Williams and Wilkins, 1949.

17 Robison LL, Buckley JD, Daigle AE, Wells R, Benjamin D, Arthur DC, et al. Maternal drug use and risk of childhood non-lymphoblastic leukemi among offspring. Cancer 1989;63:1904-11.

18 Greaves MF. Speculation on the cause of childhood acute lymphoblastic leukemia. Leukemia 1988;2:120-5.

19 Kinlen LJ, Hudson CM, Stiller CA. Contacts between adults as evidence for an infective origin of childhood leukaemia: an explanation for excess near nuclear establishments in West Berkshire? Br f Cancer 1991;64:549-54.

(Accepted 16 August 1991)

\title{
A randomised trial comparing endometrial resection and abdominal hysterectomy for the treatment of menorrhagia
}

\author{
Michael J Gannon, Edmund M Holt, John Fairbank, Michel Fitzgerald, M Alison Milne, \\ Alan M Crystal, John O Greenhalf
}

Department of Obstetrics and Gynaecology, Royal Berkshire Hospital,

Reading RG1 5AN

Michael J Gannon, MRCOG registrar

Edmund M Holt, FRCOG, consultant

John Fairbank, MRCOG, senior registrar

M Alison Milne, MB, clinical assistant

Alan M Crystal, MRCOG, consultant

John O Greenhalf, FRCOG, consultant

Regional Technical College, Galway, Republic of Ireland

Michel Fitzgerald, MSC, statistician

Correspondence to: Dr M J Gannon, University Department of Obstetrics and Gynaecology, Box No CW 34, General Infirmary, Leeds LS2 9NS.

\section{Abstract}

Objective-To determine the advantages and disadvantages of endometrial resection and abdominal hysterectomy for the surgical treatment of women with menorrhagia.

Design-Randomised study of two treatment groups with a minimum follow up of nine months.

Setting-Royal Berkshire Hospital, Reading.

Subjects -51 of 78 menorrhagic women without pelvic pathology who were on the waiting list for abdominal hysterectomy.

Treatment-Endometrial resection or abdominal hysterectomy (according to randomisation). Endometrial resections were performed by an experienced hysteroscopic surgeon; hysterectomies were performed by two other gynaecological surgeons.

Main outcome measures-Length of operating time, hospitalisation, recovery; cost of surgery; short term results of endometrial resection.

Results-Operating time was shorter for endometrial resection (median 30 (range 20-47) minutes) than for hysterectomy (50 (39-74) minutes). The hospital stay for endometrial resection (median 1 (range 1-3) days) was less than for hysterectomy (7 (5-12) days). Recovery after endometrial resection (median 16 (range 5-62) days) was shorter than after hysterectomy (58 (11-125) days). The cost was $£ 407$ for endometrial resection and $£ 1270$ for abdominal hysterectomy. Four women (16\%) who did not have an acceptable improvement in symptoms after endometrial resection had repeat resections. No woman has required hysterectomy during a mean follow up of one year.

Conclusion-For women with menorrhagia who have no pelvic pathology endometrial resection is a useful alternative to abdominal hysterectomy, with many short term benefits. Larger numbers and a longer follow up are needed to estimate the incidence of complications and the long term efficacy of endometrial resection.

\section{Introduction}

Endometrial resection is gaining widespread acceptance as a surgical treatment for menorrhagia. A survey in August 1990 showed that 36 British centres had performed a total of over 4000 endometrial ablation procedures.' Seventy per cent of these were endometrial resections with the urological resectoscope.

The technique was initially used for treating intractable uterine bleeding in women who were unfit for hysterectomy because of blood dyscrasias or extreme anaesthetic risk. ${ }^{2}$ Follow up showed that most remained amenorrhoeic. Transcervical endometrial resection was subsequently performed for healthy women who suffered from menorrhagia. ${ }^{3}$ Most of those who had a complete resection of the endometrium became amenorrhoeic. 
Endometrial resection might be an attractive alternative to hysterectomy for many women with menorrhagia. The benefits claimed for endoscopic surgery include less pain, a shorter hospital stay, and quicker recovery. ${ }^{45}$ The potential savings that might accrue from introducing endoscopic surgery in place of hysterectomy are considerable. ${ }^{56}$ The enthusiasm of surgeons and patients alike has resulted in the development and promotion of endometrial resection without controlled trials. ${ }^{7}$ We conducted a randomised controlled trial to compare endometrial resection and abdominal hysterectomy for treating women with menorrhagia.

\section{Patients and methods}

The study population consisted of women who were awaiting abdominal hysterectomy for menorrhagia at our hospital. We excluded those who were known to have leiomyomata, endometrial or cervical neoplasia, concomitant ovarian pathology, pelvic inflammatory disease, or endometriosis. ${ }^{8}$ Ethical approval for the protocol was obtained from the west Berkshire health authority ethics and research committee. Women who participated in the study gave informed consent. They were advised that endometrial resection might not render them amenorrhoeic and that if periods continued after resection contraceptive measures should be used.

Suitable women were assessed by history, physical examination, and pelvic ultrasonography with a vaginal probe. Randomisation was by sealed envelope. Women for endometrial resection were given an intramuscular injection of medroxyprogesterone acetate $150 \mathrm{mg}$ four to six weeks before surgery to reduce endometrial thickness. An intravenous injection of amoxycillin $500 \mathrm{mg}$ and clavulanic acid $100 \mathrm{mg}$ was given to both groups at induction of anaesthesia as prophylaxis against infection. The operations were performed by experienced surgeons on routine operating lists. The technique of endometrial resection has been well described elsewhere. ${ }^{9}$

Materials used during surgery were documented, and the time spent by the patient on the operating table was noted as the operating time. All patients were

TABLE I-Characteristics of women who had endometrial resection or abdominal hysterectomy

\begin{tabular}{lcc}
\hline & $\begin{array}{c}\text { Endometrial } \\
\text { resection } \\
(\mathrm{n}=25)\end{array}$ & $\begin{array}{c}\text { Abdominal } \\
\text { hysterectomy } \\
(\mathrm{n}=26)\end{array}$ \\
\hline Median (range) age (years) & $40(29-51)$ & $40(29-47)$ \\
Median (range) body mass index $\left(\mathrm{kg} / \mathrm{m}^{2}\right)$ & $24(21-39)$ & $25(20-32)$ \\
Median (range) parity & $3(0-5)$ & $2(0-6)$ \\
\hline
\end{tabular}

TABLE II-Number (percentage) of women who had had previous pelvic surgery

\begin{tabular}{lcc}
\hline & $\begin{array}{c}\text { Endometrial } \\
\text { resection } \\
(\mathbf{n}=25)\end{array}$ & $\begin{array}{c}\text { Abdominal } \\
\text { hysterectomy } \\
(\mathbf{n}=26)\end{array}$ \\
\hline Dilatation and curettage & $21(84)$ & $18(69)$ \\
Laparoscopic sterilisation & $13(52)$ & $14(54)$ \\
Caesarean section & $3(12)$ & $2(8)$ \\
Vaginal repair & $2(8)$ & $2(8)$ \\
\hline
\end{tabular}

TABLE III -Surgery and recuperation of women

\begin{tabular}{|c|c|c|c|c|}
\hline & \multicolumn{2}{|c|}{ Endometrial resection } & \multicolumn{2}{|c|}{ Abdominal hysterectomy } \\
\hline & Median (range) & Mean $(95 \% \mathrm{CI})$ & Median (range) & Mean $(95 \% \mathrm{CI})$ \\
\hline Operating time (minutes) & $30(20-47)$ & $30 \cdot 5(27 \cdot 7$ to $33 \cdot 3)$ & $50(39-74)^{\star}$ & $51 \cdot 3(48 \cdot 4$ to $54 \cdot 2)$ \\
\hline Hospital stay (days) & $1(1-3)$ & $1.4(1.2$ to 1.6$)$ & $7(5-12)^{\star}$ & $7 \cdot 1(6 \cdot 6$ to $7 \cdot 6)$ \\
\hline Analgesia time (days) & $0(0-2)$ & $0 \cdot 2(0$ to 0.4$)$ & $7(2-56)^{\star}$ & $12 \cdot 0(6 \cdot 8$ to $17 \cdot 2)$ \\
\hline Recovery time (days) & $16(5-62)$ & $21 \cdot 3(12 \cdot 5$ to $30 \cdot 1)$ & $58(11-125)^{\star}$ & $60 \cdot 6(47 \cdot 0$ to $74 \cdot 2)$ \\
\hline Return to work time (days) & $14(5-27)$ & $14.9(10.3$ to 19.5$)$ & $64(34-103)^{\star}$ & $67 \cdot 6(55.8$ to $79 \cdot 4)$ \\
\hline
\end{tabular}

${ }^{\star} \mathrm{p}<0 \cdot 001$. monitored for postoperative morbidity. ${ }^{4}$ The number of nights spent in hospital was calculated as the hospital stay. Each woman was given a diary to record any symptoms after discharge from hospital, to note the first day without analgesic drugs (analgesia time), the date at which she felt as fit as before the operation (recovery time), and the date of return to work (return to work time). Each woman was examined four months after operation, and pelvic ultrasonography was performed on patients who had had an endometrial resection. All patients were again interviewed 16 months after the start of the trial.

Seventy eight women were invited to participate. Nine did not attend for various reasons: already had hysterectomy (three women), already had endometrial resection (one), not interested (two), moved (two), pregnant (one). Sixty nine women were assessed. Three no longer complained of menorrhagia and did not require surgery. Ten were considered unsuitable because of leiomyomata (six women), ovarian cysts (four), endometriosis (one), and gross obesity (one). Two declined random allocation because of a preference for hysterectomy (one woman) and endometrial resection (one). Fifty four women were randomised, 26 to endometrial resection and 28 to abdominal hysterectomy. Three were withdrawn before operation: one woman, randomised to endometrial resection, requested hysterectomy; another, randomised to hysterectomy, requested endometrial resection; and one woman whose hysterectomy was postponed because of bed shortage was treated elsewhere.

Statistical analysis was performed by using Wilcoxon's ranked sum test appropriate for two unmatched, independent samples.

\section{Results}

Fifty one women were studied; 25 had endometrial resection and 26 underwent hysterectomy. The groups corresponded for age, height, weight, and parity (table I). They had a similar history of pelvic surgical procedures (table II). Twenty two women in each group worked outside the home: nine women who had endometrial resection and 13 who had a hysterectomy were in full time employment. Fourteen women who had endometrial resection were admitted to hospital on the day of operation; three others went home on the day of operation. Table III shows the operating time and hospital stay. No woman in either group had a blood transfusion.

There were no intraoperative or early postoperative complications in the women who had endometrial resection. The average volume of irrigating fluid $(1 \cdot 5 \%$ glycine) used during endometrial resection was $2887 \mathrm{ml}$ (range 1150-7680 ml). The fluid deficit averaged 379 (60-1440) $\mathrm{ml}$. Dilutional hyponatraemia was not recorded in any case. Vaginal bleeding after endometrial resection lasted an average of nine days (range 0-27 days). This was followed by a serosanguinous discharge for 14 (3-42) days.

Complications occurred in 12 women after hysterectomy. One woman required resuturing of the vault for haemorrhage. Early postoperative morbidity after hysterectomy included catheterisation for urinary retention (four women), urinary tract infection (two), wound infection (one), and respiratory tract infection (one). Two women later attended their general practitioners because of wound infection, and one because of vaginal discharge. Four women required cautery to vault granulation tissue, one of these under general anaesthesia.

Only four of the women who had endometrial resection required any postoperative analgesia. One woman had backache after discharge; the remainder were pain free (table III). All of the women who had a 
hysterectomy required postoperative analgesia, and four specifically noted "wind" pains. The time taken to achieve full recovery and the length of time spent off work was notably less after endometrial resection than after hysterectomy (table III). One woman took part in a county bowling competition a week after endometrial resection. The differences for surgery and recuperation between the two groups (table III) remained highly significant $(p<0.001)$ when the three women with drawn after randomisation were included on the basis of intent to treat.

The follow up after endometrial resection ranged from nine to 16 months (mean 12 months). Sixteen women $(64 \%)$ remained amenorrhoeic. Four women $(16 \%)$ had one or more light periods. One woman who had regular light menstruation after endometrial resection became pregnant and requested a termination and sterilisation. The remaining four women $(16 \%)$ did not have an acceptable improvement in symptoms and each of them had a repeat endometrial resection. All repeat resections were performed six months or more after the initial operation, and follow up ranged from two to seven months. No woman in the endometria resection group needed hysterectomy.

Table IV shows the theatre and ward costs for the operations. The average cost of theatre consumables was $£ 52$ for endometrial resection and $£ 92$ for hysterectomy; staffing and maintenance in the operating theatre cost $£ 138$ per hour; the marginal cost of a bed on the gynaecological ward was $£ 60$ per day. These variable costs account for half of all spending at our hospital. Fixed costs, including capital depreciation, hospital staffing, and energy, make up the other half

TABLE IV-Mean cost $(£)$ per operation

\begin{tabular}{lcc}
\hline & $\begin{array}{c}\text { Endometrial } \\
\text { resection }\end{array}$ & $\begin{array}{c}\text { Abdominal } \\
\text { hysterectomy }\end{array}$ \\
\hline Theatre & 244 & 418 \\
Ward & 163 & 850 \\
\hline Total & 407 & 1270 \\
\hline
\end{tabular}

The total cost of any procedure is estimated by first calculating the variable costs and then adding a factor of $100 \%$ to allow for the fixed costs.

\section{Discussion}

The benefits of endoscopic surgery were clearly shown in this study. Women experienced little or no pain after endometrial resection, less operating time was needed, and hospital stay was much shorter than after hysterectomy. Recovery after hysterectomy took nearly four times as long as recovery after endometrial resection. Women spent more than four times longer off work after hysterectomy than after endometrial resection. The hospital cost for a hysterectomy was three times that of an endometrial resection. The cost to the community in time spent off work is also considerably more for hysterectomy than for endometrial resection.

During a mean follow up of one year $16 \%$ of women had a repeat endometrial resection for persistent symptoms of bleeding or pain. Repeat operations involved removing residual or regenerating islands of endometrium by using the resectoscope. The procedure was simple and could be performed in 15-20 minutes. Those women who had a repeat resection preferred it to hysterectomy.

In women who have not been sterilised the persistence of menstruation after resection may lead to contraceptive problems. Two women requested sterilisation after endometrial resection, one of whom also had a termination of an unwanted pregnancy. When regular menstruation continues effective contraception is important. This might be achieved by early repeat resection or sterilisation.

We are unable to assess the efficacy of endometrial resection from this study, particularly as medroxyprogesterone acetate may suppress menstrual function for up to a year. ${ }^{10}$ Longer follow up may reveal more women who require repeat resection or possibly hysterectomy. Encouraging results for the long term effectiveness of endometrial ablation were reported in a recent American study, with some women followed up for eight years. ${ }^{11}$

In our larger series of 298 patients who had endometrial resection performed by a single operator up to the end of December 1990 (unpublished data) 14 is women $(4 \cdot 7 \%)$ had had a subsequent hysterectomy. $\vec{\circ}$ Seven of these failures were in the first 50 cases, and the hysterectomy rate in the subsequent 248 patients was only $2 \cdot 8 \%$. This supports the concept of a learning curve for the technique, and consistent results can be expected from the experienced operator.

The inexperienced operator is more likely to $\omega$ encounter complications such as perforation, haemor- 0 rhage, or fluid overload. ${ }^{12}$ The small number of $\overrightarrow{\vec{A}}$ patients in our study does not permit an accurate assessment of postoperative complications. Febrile morbidity seems to be more often associated with abdominal hysterectomy. Although we used prophylactic antibiotics, it is not clear that this is always necessary for endometrial resection. A previous review $Z$ detected a higher incidence of complications after abdominal hysterectomy than after vaginal hysterectomy. ${ }^{13}$ The current debate about the treatment of menorrhagia ${ }^{6}$ might well focus on the relative merits of endometrial resection and vaginal hysterectomy.

More than half of the women who undergo hysterectomy for menorrhagia have no important pelvic pathology. ${ }^{8}$ We have shown that endometrial resection can be used as an alternative to abdominal hysterectomy for these women. The health service benefits by the lower cost; the patients have a less painful procedure $\mathbb{D}$ with a shorter recuperation. The disadvantages of abdominal hysterectomy may not be acceptable in many cases for the surgical treatment of a benign condition..$^{1314}$

We thank Jenny Sleep for help in setting up the study and Sally Loveday and Sandra Falkner for secretarial assistance.

Macdonald R, Phipps J, Singer A. Endometrial ablation: a safe procedure. Gynaecological Endoscopy (in press).

DeCherney A, Diamond MP, Lavy G, Polan ML. Endometrial ablation for intractable uterine bleeding: hysteroscopic resection. Obstet Gynecol 1987;70:668-70.

3 Magos AI Baumn R, Turnbull AC. Transcervical resection of endometrium in women with menorrhagia. BMf 1989;298:1209-12. Azziz R, Steinkampf MP, Murphy A. Postoperative recuperation: relation to $D$ the extent of endoscopic surgery. Fertil Steril 1989;51:1061-4.

5 Garry R, Erian J, Grochmal SA. A multi-centre collaborative study into the treatment of menorrhagia by Nd-YAG laser ablation of the endometrium. N Brf Obstel Gynaecol 1991;98:357-62.

6 Macdonald R. Modern treatment of menorrhagia. Br $\mathcal{J}$ Obstet Gynaecol $\mathrm{W}$ 1990;97:3-7.

7 Stirrat GM, Dwyer N, Browning J. Planned trial of transcervical resection of the endometrium versus hysterectomy. Br f Obstet Gynaecol 1990;97:459.

8 Rutherford AJ, Glass MR, Wells M. Patient selection for hysteroscopic endometrial resection. Br f Obstet Gynaecol 1991-98-228-30.

en TCA Fower CG. Surgical alternatives to hysterectomy for intractable mentio Br f Hosp Med 1990;44:93-9.

10 Pardhaisong T. Return of fertility af Depo Provera: up dated data analysis. T Bioso Sci 1984:16:23-34. fectiveness of hysteroscopic treatment of menorrhagia and leiomyomas. Obstet Gynecol $\mathbb{D}$ $1991 ; 77: 591-4$

12 McLucas B. Intrauterine applications of the resectoscope. Surg Gynecol Obstet 1991; 172:425-31

3 Dicker RC, Greenspan JR, Strauss LT, Cowart MR, Scally MJ, Peterson HB, ช et al. Complications of abdominal and vaginal hysterectomy among women of reproductive age in the United States. Am F Obstet Gynecol 1982;144: $841-8$

14 Joel-Cohen SJ. The place of the abdominal hysterectomy. Clin Obstet (jynaecol $1978 ; 5: 525-43$

(Accepted 5 September 1991) 